\title{
Effects of Nicorandil on the Membrane Currents of Rabbit Sino-Atrial Node Cells
}

\author{
Hiroyasu SATOH and Keitaro HASHIMOTO \\ Department of Pharmacology, Yamanashi Medical College, \\ Tamaho, Yamanashi 409-38, Japan
}

Accepted December 23, 1983

\begin{abstract}
The effects of nicorandil (SG-75) $(3-500 \mu \mathrm{g} / \mathrm{ml})$ on the membrane potential and currents of the rabbit sino-atrial node were studied using the voltage clamp technique. Low concentrations of nicorandil $(3-10 \mu \mathrm{g} / \mathrm{ml})$ increased the action potential duration (APD) and depolarized the maximum diastolic potential (DMP), but higher concentrations had no such effects and even decreased APD and tended to hyperpolarize MDP. Regardless of these effects, nicorandil decreased the heart rate concentration-dependently. On the current systems of the sinoatrial node, $3 \mu \mathrm{g} / \mathrm{ml}$ of nicorandil decreased the outward current $\left(i_{k}\right)$, but concentrations of over $10 \mu \mathrm{g} / \mathrm{ml}$ increased it. The voltage dependency of the steadystate activation of $i_{k}$ was unchanged. Nicorandil did not affect the inward current activated by hyperpolarization $\left(I_{h}\right)$ and the slow inward current $\left(i_{s}\right)$. These results suggest that the cardiac effects induced by nicorandil must have been produced by selective change in the conductance of $\mathrm{i}_{\mathrm{k}}$.
\end{abstract}

Nicorandil (SG-75), 2-nicotinamidoethyl nitrate, is a new coronary vasodilator probably belonging to the nitrates group, and it has the advantage over other nitrates of having a long duration of action (1, 2). Unlike $\mathrm{Ca}$ antagonistic coronary vasodilators. nicorandil has been shown to have unique effects on heart muscle. Yanagisawa et al. (3-5) and Imanishi et al. (6) reported that nicorandil increased the cycle length of the spontaneous automaticity of canine Purkinje fibers and reduced the action potential duration of the canine atrial and ventricular muscles and Purkinje fibers. These authors suggested that nicorandil might have increased the potassium conductance of the cardiac muscle. Therefore, it may be of interest to directly examine the effect of nicorandil on the current systems of the sino-atrial node using the voltage clamp technique.

\section{Materials and Methods}

Rabbits of either sex, weighing 1.5-2.0 kg. were killed by a blow on the neck, and then the heart was quickly removed and a small sino-atrial node specimen of about $0.25 \times 0.25$ $\mathrm{mm}$ was prepared as has been described previously $(7,8)$.

The two microelectrode voltage clamp technique of Noma and Irisawa (7) was used. Action potentials and voltage clamp data were recorded on a storage oscilloscope (Nihon Kohden VC-10) and a pen-recorder (Nihon Kohden RJG-4124). Membrane currents were recorded using a virtual ground amplifier (118K Analog Devices) connected to a silver wire immersed in the bath. In the voltage clamp experiments, the membrane potential was held at $-40 \mathrm{mV}$, and after holding the potential for several seconds, clamp pulses were applied. The amplitudes of the time-dependent outward and inward currents were measured as the difference between the value of the current at the end of the $1 \mathrm{sec}$ pulse and the 0 current level recorded when the voltage clamp was not applied. The outward current tail after returning to the holding potential from depolarizing pulses was measured by the difference between its peak amplitude and the 0 current. 


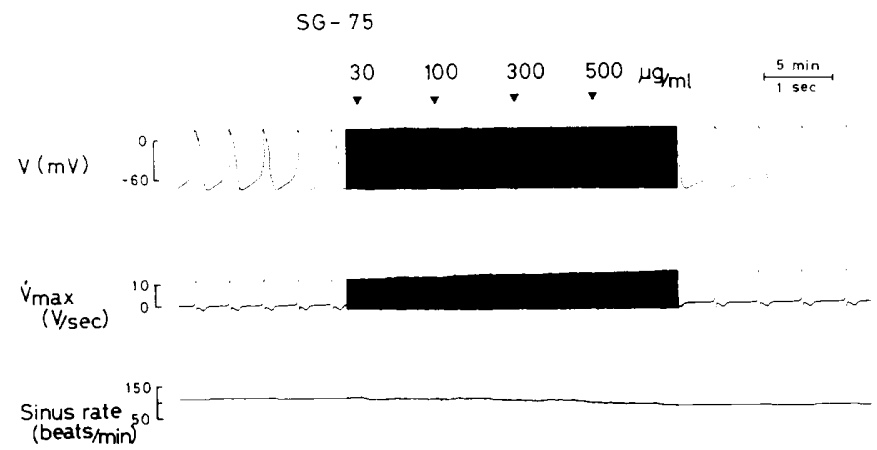

Fig. 1. Effect of various concentrations $(30-500 \mu \mathrm{g} / \mathrm{ml})$ of nicorandil (SG-75) on rabbit SA node cells. In this specimen, the maximum diastolic potential was slightly hyperpolarized, and the maximum rate of rise of action potential $\left(\dot{V}_{\max }\right)$ was elevated. The sinus rate was gradually decreased concentrationdependently.

The composition of the artificial salt solution (mM/l) was $\mathrm{NaCl}, 134 ; \mathrm{KCl}, 2.7$; $\mathrm{CaCl}_{2}$, 1.8; $\mathrm{MgCl}_{2}, 0.5$ and HEPES, 5.0. This specimen was oxygenated with $95 \% \mathrm{O}_{2}$ and $5 \% \mathrm{CO}_{2}$, and $\mathrm{pH}$ was adjusted to 7.4. The specimen was superfused at a rate of $3 \mathrm{ml} / \mathrm{min}$. The temperature of the perfusate in the recording chamber was kept at $36 \pm 1^{\circ} \mathrm{C}$. All the recordings were made $10 \mathrm{~min}$ after changing to a new solution.

All the values are expressed as the mean \pm S.E.M. Mean values were compared using Student's $t$-test for paired data, and $\mathrm{p}$ values less than 0.05 were considered significant.

\section{Results}

Effect of nicorandil on action potential of SA node cells: The effects of nicorandil, 3 to $500 \mu \mathrm{g} / \mathrm{ml}$, were examined on the action potential of rabbit SA node cells. Figure 1 shows a typical experiment showing effects of cumulative concentrations of 30 to $500 \mu \mathrm{g} /$ $\mathrm{ml}$, and the summarized data from 13 specimens are shown in Fig. 2. Low concentrations ( 3 and $10 \mu \mathrm{g} / \mathrm{ml}$ ) of nicorandil prolonged the action potential duration at $50 \%$ repolarization (APD) and depolarized the maximum diastolic potential (MDP). On the contrary, higher concentrations (30$500 \mu \mathrm{g} / \mathrm{ml}$ ) tended to decrease the APD and to hyperpolarize the MDP. However, the rate of phase 4 depolarization decreased concentration-dependently, and the cycle length of spontaneous firing was increased. Sinus

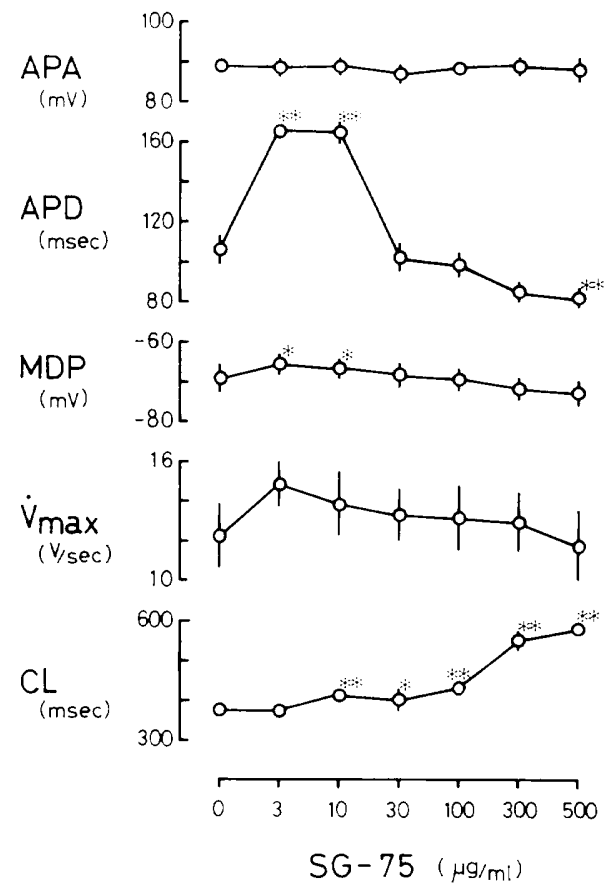

Fig. 2. Changes in the parameters of the SA node action potential by nicorandil (SG-75) $(n=13)$. Low concentrations ( 3 or $10 \mu \mathrm{g} / \mathrm{ml}$ ) increased the action potential duration (APD) and reduced the maximum diastolic potential (MDP). On the other hand, higher concentrations $(30-500 \mu \mathrm{g} / \mathrm{ml})$ decreased APD and tended to hyperpolarize MDP. The cycle length (CL) was prolonged concentration-dependeritly. Vertical bars represent the S.E.M. ${ }^{*} P<0.05$, ${ }^{*} P<0.01$, significantly different from basal values. 
arrest, which was often induced by antiarrhythmic drugs $(8,9)$, was not induced by up to $500 \mu \mathrm{g} / \mathrm{ml}$ nicorandil.

Effect of nicorandil on the membrane currents of SA node cells: In order to examine the effects of nicorandil on the membrane currents, voltage clamp experiments were performed on 5 specimens. As in Fig. 3, the membrane potential was held at $-40 \mathrm{mV}$ and then depolarizing or hyperpolarizing pulses, which were changed in $10 \mathrm{mV}$ steps, of $1 \mathrm{sec}$ duration were applied before and after exposure to nicorandil. A low concentration of $3 \mu \mathrm{g} / \mathrm{ml}$ reduced the timedependent outward current $\left(i_{k}\right)$ and the outward current tail. However, higher concentrations $(10 \mu \mathrm{g} / \mathrm{ml}$ and more) increased them concentration-dependently, and the results of Fig. 3 were plotted against the potential of the clamp pulses in Fig. 4A $\left(i_{k}\right)$ and 4B (outward current tail). The inward current which was activated by the hyperpolarization pulse from the holding potential $\left(i_{h}\right)$ was almost unchanged as shown in the current-voltage curves more negative than $-40 \mathrm{mV}$ in Fig. 4A. Nicorandil did not affect the slow inward current ( $i_{\mathrm{s}}$ ), as shown in the transient downward current traces in Fig. 3, observed soon after the depolarizing pulse from -40 to $0 \mathrm{mV}$. This result is con-

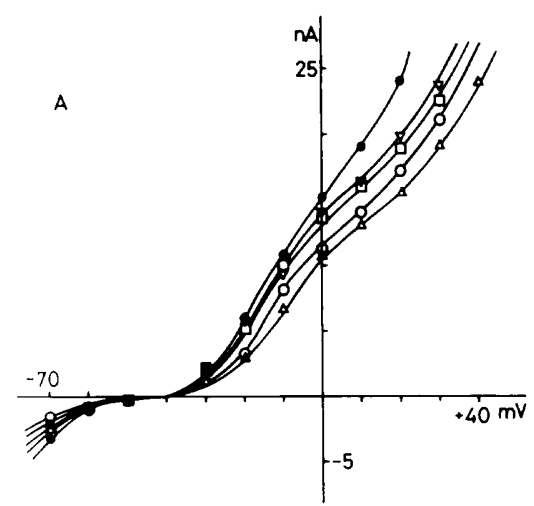

sistent with the action potential recording experiments that nicorandil did not change the maximum rate of rise of the SA node action potential $\left(\dot{V}_{\max }\right)$. In order to examine whether nicorandil altered the voltage dependency of $i_{k}$, the peak of the outward current tail was plotted against the clamp pulse potential, as in Fig. $4 \mathrm{~B}$, but by nor-

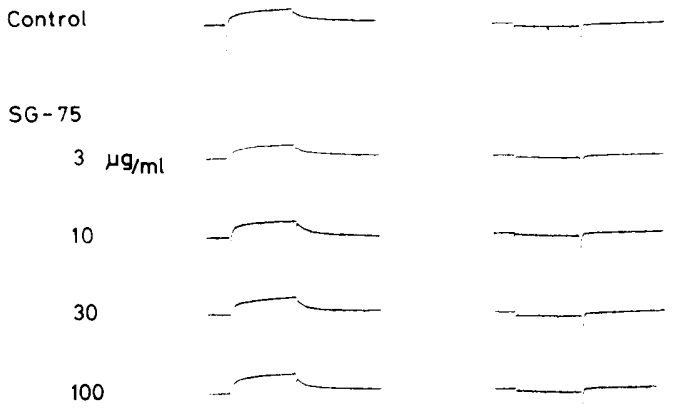

Fig. 3. Effect of nicorandil (SG-75) on the steadystate currents of the SA node cells. The membrane potential was held at $-40 \mathrm{mV}$. Depolarizing or hyperpolarizing clamp pulses of $1 \mathrm{sec}$ were applied by $10 \mathrm{mV}$ steps.

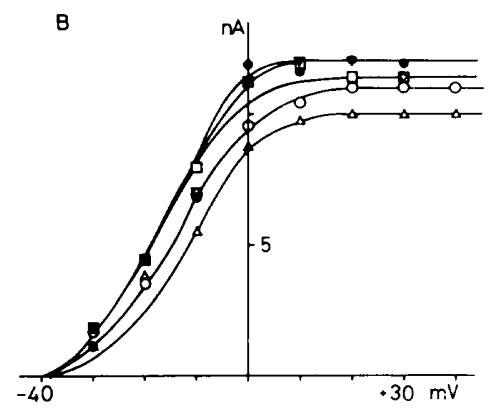

Fig. 4. Voltage-dependency of the nicorandil induced changes in the time-dependent outward current and the outward current tail. A: current-voltage relations for the outward current at various concentrations were plotted from Fig. 3. Three $\mu \mathrm{g} / \mathrm{ml}$ of nicorandil $(\triangle)$ decreased the outward current, but $10 \mu \mathrm{g} / \mathrm{ml}$ or higher concentrations increased it. The inward current activated by hyperpolarization was almost unchanged. B: Effect of nicorandil on the outward current tail was also plotted from Fig. 3. Three $\mu \mathrm{g} / \mathrm{ml}$ of nicorandil $(\triangle)$ decreased the outward current tail, but the higher concentrations increased it. The symbols used in the figure represent before $(O)$ and after exposure to $10 \mu \mathrm{g} / \mathrm{ml}(\square) .30 \mu \mathrm{g} / \mathrm{ml}$ $(\nabla)$ and $100 \mu \mathrm{g} / \mathrm{ml}$ of (O) nicorandil. 


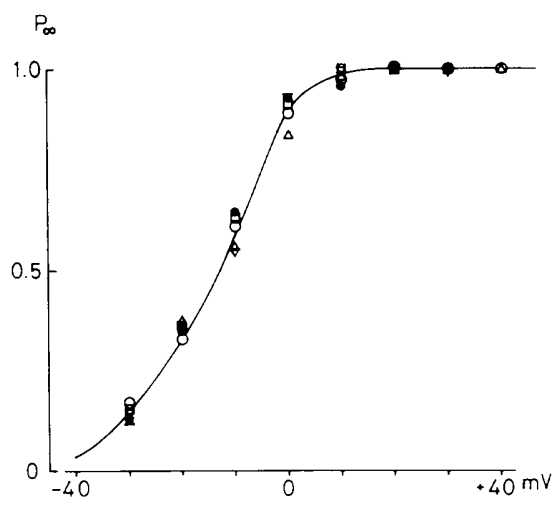

Fig. 5. Normalized outward current tails (ordinate) plotted as a function of the clamp potential (abscissa). When all data in Fig. 4B were normalized, the curves can be fitted in a single sigmoidal curve. Symbols are the same as those in Fig. $4 \mathrm{~A}$ and $B$.

malizing with reference to the tail current at $+20 \mathrm{mV}$ as $1.0\left(\mathrm{p}_{\infty}\right)$ in Fig. 5. The curves in Fig. 4B fitted in a single sigmoid curve, indicating that nicorandil did not change the voltage dependent characteristics of $i_{k}$ and that the changes in $\mathrm{i}_{\mathrm{k}}$ were due to the changes in the conductance of $i_{k}$ channels.

\section{Discussion}

The vasodilator property of nicorandil has already been demonstrated $(1,2,10,11)$, and the mechanism of the vasodilatation has been proposed to be due to increase in cyclic GMP (12) without affecting cyclic AMP phosphodiesterase (13). Cholinomimetic properties of SG-75 on the cardiac tissue have been reported (3-6), and our results on the action potential of the rabbit SA node cells by higher concentrations of nicorandil are consistent with these reports, i.e., the action potential duration tended to decrease and the maximum diastolic potential tended to hyperpolarize. This action potential change might have been produced by the increase in the steady-state outward current $\left(i_{k}\right)$ by higher concentrations of nicorandil $(10 \mu \mathrm{g} /$ $\mathrm{ml}$ or more). Such an increase in $\mathrm{i}_{\mathrm{k}}$ is known to be produced by cholinomimetic agents $(14,15)$, accompanied by an increase in intracellular cyclic GMP (12), though nicorandil was not affected by atropine
(4-6). Such a change in the outward current could have been produced electrophysiologically either by a change in the voltage dependency of the activation of $i_{k}$ or a change in the conductance of $i_{k}$. Since the voltagedependency of the activation of the steadystate current $\left(p_{\infty}\right)$ was not affected by nicorandil, nicorandil must have increased the conductance of the $i_{k}$ channel, possibly increasing the number of $i_{k}$ channels. The unexpected increase in the action potential duration and depolarization of the maximum diastolic potential by low concentrations of nicorandil can also be explained by the change in $i_{k}$, in this case by the observed decrease in $i_{k}$. For other current systems, nicorandil did not affect the slow inward current $\left(i_{s}\right)$ and the inward current activated by hyperpolarization $\left(i_{h}\right)$. Though using different cardiac tissues, our voltage clamp results confirmed previous suggestions that nicorandil selectively increases the potassium conductance (3-7).

As for the negative chronotropic effect of nicorandil, statistically significant changes were produced only by higher concentrations and nicorandil had no effect on $i_{s}$; therefore, it is most probable that the increase in $i_{k}$ hyperpolarized the maximum diastolic potential and decreased the slope of phase 4 depolarization, resulting in the decrease in the firing rate.

Acknowledgement: The authors thank Chugai Pharmaceutical Co., Ltd., for the supply of nicorandil and also thank Mrs. Y. Hashimoto and Mr. J. Sendoda for their help in preparing the manuscript. This work was supported by a research grant from the Japanese Ministry of Education.

\section{References}

1 Uchida, Y., Yoshimoto, N. and Murao, S.: Effect of 2-nicotinamidethyl nitrate (SG-75) on coronary circulation. Japan. Heart J. 19, 112-124 (1978)

2 Taira, N., Satoh, K., Yanagisawa, T., Imai, Y. and Hiwatari, M.: Pharmacological profile of a new coronary vasodilator drug, 2-nicotinamidoethyl nitrate (SG-75). Clin. Exp. Pharmacol. Physiol. 6, 301-316 (1979)

3 Yanagisawa, T., Satoh, K. and Taira, N.: Circumstantial evidence for increased potassium conductance of membrane of cardiac muscle by 2-nicotinamidoethy! nitrate (SG-75). Japan. J. 
Pharmacol. 29, 687-694 (1979)

4 Yanagisawa, T. and Taira, N.: Effect of 2 nicotinamidethyl nitrate (SG-75) on membrane potentials of canine Purkinje fibers. Japan. J. Pharmacol. 31, 409-417 (1981)

5 Yanagisawa, T. and Taira, N.: Effect of 2nicotinamidethyl nitrate (SG-75) on the membrane potential of left atrial muscle fibres of the dog: Increase in potassium conductance. Naunyn Schmiedebergs Arch. Pharmacol. 312, 69-76 (1980)

6 Imanishi, S., Arita, M., Kiyosue, T. and Aomine, M.: Effects of SG-75 (nicorandil) on electrical activity of canine cardiac Purkinje fibers: Possible increase in potassium conductance. J. Pharmacol. Exp. Ther. 225, 198-205 (1983)

7 Noma, A. and Irisawa, H.: A time- and voltagedependent potassium current in the rabbit sinoatrial node cell. Pfluegers Arch. 366, $251-$ 258 (1976)

8 Satoh, H. and Hashimoto, K.: Effect of propafenone on the membrane currents of the rabbit sino-atrial node cells. Eur. J. Pharmacol. (in press)

9 Satoh, H., Nakajima, T., Hashimoto, K. and Imai, S.: Effects of lidocaine and procaine on the action potential of canine sinus nodal cells. Japan. Heart J. 22, 929-937 (1981)

10 Thormann, J., Schlepper, M., Kramer, W.,
Gottwik, M. and Kindler, M.: Effectiveness of nicorandil (SG-75), a new long-acting drug with nitroglycerin effects, in patients with coronary artery disease: Improved left ventricular function and regional wall motion and abolition of pacing-induced angina. J. Cardiovasc. Pharmacol. 5, 371-377 (1983)

11 Itoh, T., Furukawa, K., Kajiwara, M., Kitamura, K., Suzuki, H., Itoh, Y. and Kuriyama, H.: Effects of 2 -nicotinamidoethyl nitrate on smooth muscle cells and on adrenergic transmission in the guinea-pig and porcine mesenteric arteries. J. Pharmacol. Exp. Ther. 218, 260-270 (1981)

12 Holzmann, S.: Cyclic GMP as possible mediator of coronary arterial relaxation by nicorandil (SG-75). J. Cardiovasc. Pharmacol. 5, 364-370 (1983)

13 Endoh, M., Yanagisawa, T. and Taira, N.: Effects of 2-nicotinamidethyl nitrate (SG-75), a new antianginal drug, on the cyclic AMP phosphodiesterase activity. Tohoku J. Exp. Med. 130, 199-201 (1980)

14 Burgen, A.S.V. and Terroux, K.G.: On the negative inotropic effect in the cat's auricle. J. Physiol. (Lond.) 120, 449-464 (1953)

15 Trautwein, W. and Dudel, J.: Zum Mechanismus der Membranwirkung des Acetylcholin an der Herzmuskelfaser. Pfluegers Arch. 266, 324-334 (1958) 